\title{
Celso Furtado, o retorno à polêmica fundamental
}

\section{FERNANDO PEDRÃO*}

Celso Furtado, the return to the basic controversy. A reading of the work of Celso Furtado in its completion opens an enriching view of the interaction between theoretical thinking and the unveiling of Latin-America history. Starting from an appraisal of the pre-Classic and Classic authors, Furtado outlined an approach of surplus theory. That would enable development theory to deal with the unevenly industrialized economies like Brazil. His thorough analysis of development and underdevelopment processes broke away from the initial ECLA experiences to build a planning proposal the uprising country. The French roots of his academic profile helped him to keep an orderly explanation of capital demand that kept him siding with Wicksell against the subjective theory of Schumpeter.

Keywords: surplus theory; underdevelopment process; capital accumulation. JEL Classification: O11.

Quando o homem volta à sua terra depois de muitos anos de peregrinações e lutas fora, apoia-se em suas pedras ancestrais e estende seu olhar sobre as regiões familiares. Nikos Kazantzakis

\section{IDENTIDADE NACIONAL E POLÊMICA FUNDAMENTAL}

A leitura da obra de Furtado constitui uma oportunidade ímpar para colocar o processo nacional como um tema que se desenha através de uma polêmica fundamental acerca de desenvolvimento econômico e social e expõe a relação entre a

\footnotetext{
* Doutor e docente livre (aposentado) da UFBA, presidente do Instituto de Pesquisas Sociais, professor visitante da Universidade Federal do Recôncavo. E-mail: fernandopedrao@gmail.com. Submetido: Setembro 2009; Aprovado: Novembro 2009.
} 
identidade nacional e as condições sociais do desenvolvimento. Celso Furtado se inicia como um intelectual oriundo da periferia tradicional do Brasil, já com uma influência decisiva da visão francesa de mundo do após guerra. Naquele mundo em transformação, onde se perfilava a influência da uma visão de reconstrução e progresso de uma combinação de ideais e modos de cultura ingleses e nórdicos, surgiam pressões reivindicatórias de descolonização da Índia, do Egito e da Indonésia, que contrastavam com o ambiente de desconfiança entre o Leste e o Oeste, onde a necessidade de mudar era alimentada pela impossibilidade de restaurar a anterior ordem do poder mundial. Desenvolvimento se apresentava como tema fundamental em torno do qual se colocaram todos os demais. A busca de uma teoria geral do desenvolvimento é concomitante com a descolonização e a entrada em cena de nações marginalizadas pelo anterior sistema imperial.

Surge uma questão mundial de época, relativa à possibilidade de se desenvolver uma teoria geral do desenvolvimento indo de encontro com a perspectiva da teoria econômica reconhecida como científica, que considerava o desenvolvimento como um tema subordinado ao do comércio internacional, tal como expresso por Hicks (1965). Mais grave ainda, a possibilidade de uma teoria que tratasse com a variedade de situações revelada pela descolonização, portanto, que transcenda os termos consagrados do capitalismo. Significava questionar o capitalismo como um sistema que gera exploração e desvalorização social. Tal teoria não cairia em contradição com a própria historicidade do capitalismo? Pelo modo como toma esse desafio, para Furtado essa teoria é necessária à construção de nossa identidade e precisa reconhecer a crescente complexidade do sistema socioprodutivo, por isso, descartando aquela dinâmica simplificadora que pretende realizar-se integralmente no mundo do capitalismo. Vislumbra-se aí um trabalho hercúleo que descartará o marginalismo, que fará uma revisão seletiva do campo keynesiano e uma garimpagem no marxismo para descartar o dogmatismo e o eurocentrismo ${ }^{1}$. É uma simplificação indevida rotular de desenvolvimentismo esse esforço de reconstituição histórica, de negar o que ele significa como revisão dos fundamentos da economia clássica e como contribuição a uma teoria do desenvolvimento que procura integrar a acumulação de capital e a distribuição da renda. A grande dificuldade estaria em encontrar termos de comparação entre o excedente físico nas economias não industriais e nas indústrias onde ele já é valorado monetariamente. A valoração do trabalho na produção industrial, tal como revelaram os estudos da CEPAL sobre os países latino-americanos, enfrenta um problema imprevisto de falta de comparabilidade nos usos do tempo, que reverte às condições de comparação, por exemplo, entre o trabalho de camponeses e mineiros submetidos às encomiendas, e o trabalho dos minifundistas da produção familiar. Esse problema se reproduz em diversas condições espaçotemporais, como Mariategui apontou no Peru e como a CEPAL encontrou na Bolívia em 1958 e no México em 1957, quando encontraram estruturas agrárias arcaicas inseridas em sistemas capitalistas de produção.

\footnotetext{
${ }^{1}$ Nessa perspectiva de crítica histórica cabe hoje referir a José Arthur Gianotti (2009), que vê a obra de Marx como um imenso trabalho inconcluso e que resiste às contradições do ambiente político.
} 


\section{ELEMENTOS ESSENCIAIS DO PERCURSO}

Para captar o significado da obra dos grandes pensadores é preciso situá-los em sua época e observar a progressão de seu trabalho. Esta abordagem progressiva, iniciada por Werner Jager ${ }^{2}$, é essencial aqui, porque o processo da obra de Celso Furtado se confunde com os tempos de transformações decisivas da economia brasileira. Como disse Francisco Iglésias (Furtado, 1997) no prefácio à Obra Autobiográfica de Furtado, ele representa a geração que surgiu depois da revolução de 30, da qual foi o pensador mais poderoso. Para apreciar a importância da obra de Celso Furtado é preciso colocá-la na formação da teoria do desenvolvimento.

Há dois aspectos a ressaltar nesta incursão ao mundo de Celso Furtado: a grande evolução em seu caminho de intelectual e a alternância de um pensar especulativo com uma vontade de um agir historicamente significativo. Observe-se que a luta por uma teoria civilizacional do desenvolvimento teria que passar pelo purgatório de uma pesquisa histórica exaustiva sobre a América Latina, que vinha sendo esquivada por todos os economistas de plantão, cuja falta continua até hoje. Ocorre que a complexidade do mundo latino-americano reconhecido pela ciência social começava a aparecer na década de 1950, registrada na separação entre o horizonte dos estudos econômicos e o dos estudos socioantropológicos. Os dois campos pouco se comunicavam e a Formação Econômica foi o primeiro livro de economia que sublimou os conflitos conceituais levantados pela primeira rodada de estudos da CEPAL. Impõe-se registrar a contribuição de José Medina Echevarria com o tratamento dado aos processos sociais do subdesenvolvimento ${ }^{3}$, que seriam uma combinação de efeitos da colonização com mecanismos internos de exploração, principalmente da estrutura fundiária. A grande propriedade rural foi a referência básica do sistema colonial, mas não veio pronta da Europa, onde não havia latifúndios com as extensões que passaram a ser referências na América. Desde o século XVII a exploração agrária tornara-se um mecanismo interno na maior parte da América Latina e que no Brasil a própria escravização tornara-se um negócio conduzido por brasileiros ${ }^{4}$.

As referências interativas ao que chamo de Primeira CEPAL - a de Prebisch, que acabou em 1973 - são fundamentais, porque demarcam o fim de um esforço contestatório e sua substituição por burocracia e alinhamento com o poder hegemônico. Com limitações de informações e de conhecimento reconhecidas pelo próprio Prebisch ${ }^{5}$, a CEPAL se dispôs a construir um sujeito histórico da formação da América Latina que envolvia a superação de problemas internos da região, tais como a relação do mundo pós-colonial com o mundo indígena e como a ruptura

\footnotetext{
${ }^{2}$ Trata-se do estudo sobre Aristóteles, que lançou esse modo de análise biográfica (Jager, 1984).

${ }^{3}$ Medina coordenou o estudo de análise e projeções do desenvolvimnento da Bolívia em 1958.

${ }^{4}$ Sobre esse ponto, vale ver de Luiz Felipe Alencastro (2000).

${ }^{5}$ Em 1970 Prebisch mobilizou um grande número de economistas e sociólogos, com o objetivo de realizar uma nova interpretação do continente latino-americano, em um esforço que foi interrompido por pressões políticas.
} 
entre a América urbana - branca - e a América rural — índia. Com isso, suscitou um problema histórico da economia que não resolveu, mas que foi reconhecido e tomado por Furtado em uma tentativa de produzir uma outra síntese histórica do processo formativo da economia do continente ${ }^{6}$. Os sucessivos movimentos de entrada de capitais com formas de organização modernizada tomaram novo impulso desde a chegada da Família Real ao Brasil, que funcionou como uma plataforma para investimentos ingleses, representando um padrão territorial que se apoiava nas vantagens estratégicas do Rio de Janeiro ${ }^{7}$.

O principal papel de Celso Furtado foi de definir uma linha consistente da polêmica fundamental sobre o desenvolvimento, mediante um eixo de especulação teórica que começa com os seus artigos de 1953 a 1956, está embutido em A Economia Brasileira (1954b) e no artigo de resposta a Nurkse (1964). Mas aflora em Desenvolvimento e Subdesenvolvimento (1961) e alcança seu ponto máximo em Prefácio a uma Nova Economia Política (1976). Em toda sua obra, buscará respostas para problemas seculares das transformações dos sistemas produtivos, onde o lugar central será sempre a relação entre dominantes e dominados em suas sucessivas formas, desde o ambiente mercantil ao da industrialização forçada, entendendo que mudam as condições concretas de apropriação do excedente (1956c). O foco da análise ficará consistentemente no eixo excedente $\longrightarrow$ acumulação $\longrightarrow$ custo social de reprodução do trabalho simples. A análise se fechará na relação acumulação $\longrightarrow$ desenvolvimento.

O ambiente histórico foi decisivo na determinação de uma agenda de questionamentos que se formulavam à sombra da expansão da influência norte-americana, quando o Plano Marshall parecia ser uma alternativa melhor que a política de Geoge Kennan. A experiência dos anos de 1949 a 1958 foi muito intensa e o discurso de vanguarda sobre o desenvolvimento tomou novos rumos ${ }^{8}$. A noção de crise estava latente na percepção das limitações do desenvolvimento na concentração do capital, mas só se tornou um discurso próprio, explícito e consistente em Transformação e Crise da Economia Mundial, Furtado, 1987). Anos mais tarde, em Raizes do Subdesenvolvimento (Furtado, 2002), voltará a avaliar a Guerra Fria, propondo-se desmistificar a tensão mundial, colocando-a mais como um fator de delimitação do poderio norte-americano.

Desde então o trabalho de Furtado reflete essa preocupação com a linha de tensão entre os aumentos de produtividade e a renda familiar. Simplificando suas próprias palavras (Furtado, 1976, p. 19), o custo do trabalho simples determina o custo da reprodução simples. A seguir (Furtado, 1976, pp. 21), que o comporta-

\footnotetext{
${ }^{6}$ De qualquer modo, ainda surpreende a falta de comunicação entre os estudos econômicos e os históricos, que tiveram o curioso efeito de que em cada país se passasse a depender de fontes externas, para uma mínima aproximação do passado secular do continente e houvesse escassa comunicação entre países vizinhos.

${ }^{7}$ Esse processo foi amplamente examinado em História Geral da Civilização Brasileira, II. O Brasil monárquico, 1. O processo de emancipação (Holanda, 1993).

${ }^{8} \mathrm{O}$ único intelectual europeu que trouxe material empírico novo foi Myrdal, com seus estudos sobre os negros norte-americanos na década de 1950 e sobre o sul da Ásia na década de 1960.
} 
mento no tempo desse custo de reprodução depende de quanto os trabalhadores conseguem se apropriar de seus ganhos de produtividade, isto é, quanto conseguem reverter a taxa de exploração. Ora, essas condições de distribuição dos ganhos de produtividade se realizavam em condições de expansão da economia mundial, em que as condições internas de atraso das economias latino-americanas tornavam-se relativamente mais graves.

Furtado focaliza no conceito de excedente, mas o fantasma que ele persegue desde a Economia Brasileira é a taxa de exploração na economia periférica, que ele procura mapear na ruptura entre a industrialização e a repetição do sistema agro-mercantil. A interrupção da industrialização nos estados do Nordeste obriga a procurar explicações em situações nacionais e internacionais. As conotações sistêmicas da relação capital/trabalho estão presentes desde sua obra anterior à SUDENE e chegam a sua plena maturidade em Racionalidade e Dependência e no Prefácio a uma Nova Economia Política. Também, do período anterior ao ensaio "Uma política de desenvolvimento econômico e social para o Nordeste", estão os artigos do Trimestre Econômico em que se sente a diferença entre a abrangência do pensamento do grupo francês de que ele foi aluno e parte, onde pontuaram André Marchal, Alain Barrère, Maurice Byé e François Perroux, comparado com a visão mecanicista e preconceituosa norte-americana, de que vinham Ahumada, Mayobre e vários outros. A dimensão cultural da obra de Furtado já se delineava junto com a abordagem histórica desde a Formação Econômica do Brasil, mas era uma parte essencial da consciência da complexidade social do Brasil (Furtado, 1954b, p. 9).

A perspectiva mundial de então não se confunde com a da globalização. Enquanto a primeira enfeixa as controvérsias da Terceira Internacional a segunda consagra a diluição das contradições que se escondem sob o manto da hegemonia do capital financeiro. A construção de uma teoria do desenvolvimento teria que trabalhar com a solidez das economias nacionais. Prebisch percebeu isso com clareza, mas no essencial ele trabalhava com referências da Argentina e do Chile, que tinham tido sua prosperidade decepada pela crise de $30^{9}$, enquanto Furtado pensava a experiência brasileira, que sofrera desgaste desde 1914 com o fechamento do mercado europeu para café, fumo e cacau e que em 30 já estava no fundo do poço. Para Prebisch, desenvolvimento significava restaurar condições de prosperidade perdidas ${ }^{10}$, enquanto para Furtado era uma teoria mundial e significava reverter tendências negativas que tinham expressões internacionais e internas, tal como aparece em suas observações sobre a Campania (Furtado, 1997 vol. I, p. 15). Para Prebisch desenvolvimento é um movimento que envolve modificações do comércio e industrialização, enquanto para Furtado é um movimento que começa

\footnotetext{
${ }^{9}$ Os exemplos do Chile são decisivos no relativo à destruição do grupo social ligado à grande mineração, que ficou totalmente desativado com a crise de 1930. A "chilenização" do cobre, iniciada por Ahumada no governo Frei foi a peça unificadora dos interesses externos na formação do golpe militar no Chile.

${ }^{10}$ Ver os ensaios contidos no volume intitulado O pensamento da CEPAL (Pedrão et al., 1988a; Pedrão, 1988b).
} 
pela superação do controle do excedente na agricultura, que é onde se encontra a maior parte do trabalho simples. Será necessária uma reflexão muito mais cuidadosa sobre o material da obra reflexiva de Furtado, que descreve um movimento de vai e volta entre o generalismo de uma visão mundial francesa e o particularismo das afirmações das nações latino-americanas, que passava por cima desse fosso.

\section{A TEORIA DO EXCEDENTE E A GRANDE TEORIA DO DESENVOLVIMENTO}

A teoria do excedente em Furtado é essencial a uma revisão da noção de acumulação que, por sua vez, é o ponto de partida de uma teoria geral do desenvolvimento. Ao referir-se ao conjunto das formas de acumulação e não só àquelas que acrescentam capital, lançava os desafios a serem enfrentados por essa teoria geral, que teria que se contrapor ao projeto europeu e norte-americano de modernização. Em pauta está a concepção do processo social de acumulação de capital, que compreende o modo como ela se realiza e a totalidade do que ela se compõe. Furtado lança os elementos de uma linha conceitual cuja abrangência permite tratar com as formas de acumulação da produção simples junto com a de alta tecnologia, com a acumulação nos ambientes pré-capitalistas junto com a dos ambientes capitalistas.

A construção de uma teoria desse calibre é o fundamento da grande polêmica acerca do desenvolvimento, que trata da relação entre a acumulação de capital e as transformações do sistema produtivo, isto é, do desenvolvimento das forças produtivas. Por extensão, trata da inter-relação entre a acumulação de capital e a distribuição da renda. Noutras palavras, entre a acumulação de capital e o desenvolvimento do mercado, entendendo que mercado significa uma distribuição social do poder de compra. O movimento geral de concentração que caracteriza o capitalismo avançado denota uma tendência socialmente negativa do processo econômico no quadro desigual da economia mundial. A teoria do crescimento não entra no mérito desses problemas e a teoria do desenvolvimento elaborada nos países centrais presume que essa tendência é inevitável ou que não há alternativa para ela.

A proposta de trabalho teórico de Furtado é a maior de quantas tenham aparecido na América Latina, remetendo-se aos fundamentos da grande teoria do desenvolvimento, que ultrapassa a teoria do desenvolvimento do capitalismo. Desenvolvimento será um fenômeno civilizacional, tal como foi para Vico: a riqueza dos governantes ou a dos homens comuns? A viagem teórica de Furtado tinha que se apoiar em refundações, revisões de conceitos (Furtado, 1968a, pp. 41-78), quando usa uma determinada interpretação dos "alicerces do subdesenvolvimento" para construir uma visão própria de excedente (Furtado, 1976, pp. 27-32) que abrange uma morfologia da colonização.

Para alcançar essa tarefa maior, Furtado desenvolve uma teoria do excedente — que também foi simplificada por alguns de seus comentaristas - abrangendo situações de produção pré-capitalista, capitalista e socialista. Furtado vincula o eixo produção - captação de excedente às condições políticas de formação do mercado. A rigor trata-se de identificar o movimento de acumulação na produção 
mercantil, superando a suposta limitação do capital mercantil para acumular. Para esclarecer esse suposto hiato, Celso Furtado toma o conceito de acumulação em que resgata a acumulação estoque ante a acumulação fluxo. A teoria do excedente em Furtado surge de um retorno aos Fisiocratas e é uma crítica das dimensões do sistema produtivo ante a população total, que logicamente serve como ferramenta crítica do colonialismo. Para ele o excedente se vê pela relação do sistema produtivo com a população total, onde, portanto, há uma relação crucial entre as transformações da população e as da capacidade produtiva. O cálculo do excedente surge da relação entre o custo social da reprodução da força de trabalho comparado com a produtividade social do trabalho. Uma relação entre os resultados dos trabalhadores incorporados à produção capitalista com a sobrevivência de todos que dependem de trabalhar. Não se trata somente da exploração dos que trabalham, mas de como a exploração dos que trabalham funciona como modo de controle do consumo da população em seu conjunto.

Nesse discurso faltou explorar as inter-relações entre a relação excedente-exploração no segmento arcaizado e no modernizado, que se realiza mediante a mobilidade dos trabalhadores. Encontra-se uma unificação do mercado de trabalho que opera através dos grupos de baixa renda. As condições específicas de exploração estarão dadas pela pressão de demanda de postos de trabalho frente à flexibilidade da capacidade de absorção de trabalhadores novos.

\section{UMA TEORIA PARA O PLANEJAMENTO}

A luta por uma teoria para o planejamento começa praticamente ao mesmo tempo em que pela teoria do desenvolvimento, tal como ficara claro no planejamento da União Soviética com Lenin na década de 1920. A visão de desenvolvimento seria crucial na montagem do planejamento da SUDENE anos depois, quando Furtado se distanciou da abordagem habitual da CEPAL. A SUDENE do primeiro plano diretor representou um estilo de planejamento inovador, dirigido para ampliar a base de incorporação de mão de obra ao processo produtivo. Para entender esse processo do planejamento aqui é preciso voltar aos seus antecedentes. Por trás das opções de técnicas de planejamento houve uma linha principal de opção por uma planificação de economias de guerra desenvolvida pelos soviéticos na modalidade de balanços de materiais e de projetos de propósito múltiplo, que se comparava com as opções de planejamento indicativo representadas pela opção francesa pragmática do Plano do Carvão e do Aço e pelas versões nórdicas de modelagem econométrica. O esquema de Feldman é da década de 1920, como também o complexo Orel-Kuznetsk ${ }^{11}$. Autores como Lewis apregoavam um planejamento em ambiente de mercado aberto, enquanto Strumilin - citado por Furtado - representavam o planejamento soviético centralmente dirigido. Barre em 1957 apresentava um tratado de Economia Política com análise comparativa dos

\footnotetext{
11 Os norte-americanos seguiriam esse modelo na década de 1940 com a constituição da Superintendencia do Vale do Tennesssee.
} 
dois sistemas. Na Primeira CEPAL Celso Furtado dirigiria a elaboração do primeiro manual de planejamento daquele órgão.

A proposta de Furtado de construir uma grande teoria do desenvolvimento começou a se esboçar com o artigo de 1954, intitulado "A teoria do desenvolvimento na evolução da teoria econômico" ${ }^{12}$, foi retomado de modo sistemático em Teoria e política do desenvolvimento econômico em 1968a e alcançou sua forma mais desenvolvida em Prefácio a uma Nova Economia Política de 1976. Mas é um trabalho inconcluso, tal como se infere de comentários inseridos na Obra Autobiográfica vol.II, quando ele aponta à crise de sentido de finalidade da teoria. A teoria do desenvolvimento teria que considerar a incorporação dos efeitos da distribuição no crescimento, assim como teria que reconhecer os efeitos acumulativos da renovação técnica em emprego e renda, que é o significado da mais valia relativa de Marx. O recrudescimento da ortodoxia conservadora em economia no Brasil levou a leituras condescendentes da polêmica fundamental que hoje se revisam.

Há boas razões para pretender que alguns estudos sobre a obra de Furtado, inclusive em que se pretende focalizar em seus aspectos teóricos, passaram por alto os fundamentos desse esforço teórico, possivelmente por não observarem o processo da obra ou a evolução do pensamento teórico de nosso autor, que se remete a uma leitura crítica dos fundamentos pré-clássicos da teoria. Trata-se de que Celso Furtado realizou um mergulho na formação histórica da teoria, resgatando dimensões conceituais da obra dos Fisiocratas, de Say, J.S.Mill, como pano de fundo de uma leitura criativa da obra de Marx. Mas introduziu uma modificação sutil, ao denunciar a diferença entre a acumulação fluxo que alimenta a concentração de capital e a acumulação estoque, que reflete as diferenças de engajamento de trabalho na subsistência e na produção de mercadorias.

A questão central se coloca em torno da relação entre uma teoria do excedente, uma crítica da teoria da acumulação e de seus desdobramentos em distribuição da renda. Especificamente, toma a distribuição da renda em suas consequências radicais na renda do trabalhador pobre, que corresponde ao trabalho simples. Descarta a dinâmica econômica linear à la Harrod, propondo-se trabalhar com a complexidade própria dos processos históricos, onde a renda do trabalhador pobre não é um dado invariante. Essa leitura sintética da acumulação só seria possível enquanto se aceitasse como consistente a ideia de que tanto a taxa de lucro como a de salário corresponderiam a uns mesmos elencos de bens e serviços.

A teoria da acumulação estoque é fundamental no pensamento de Furtado, porque informará sua concepção de planejamento, voltada que foi para deslocar o controle social do excedente através da elevação do custo social do trabalho simples. A acumulação estoque à materialização dos processos de acumulação em ativos fixos, mas igualmente descreve a validade histórica dos equipamentos, subsumindo as inter-relações técnicas entre os diversos equipamentos, indiretamente situando as condições de qualificação do trabalho.

Nesse quadro seria preciso criar uma nova proposta de desenvolvimento. Não só uma reversão das tendências da estrutura fundiária, como realizar a ligação

${ }^{12}$ Furtado, 1954a. 
entre as tendências à expulsão de trabalhadores do meio rural, como realizar a relação entre esse tipo de mobilidade do trabalho com os salários urbanos e com o reconhecimento dos efeitos historicamente essenciais da marginalização convertida em antieconomia do crime.

Os instrumentos disponíveis de política regional não foram suficientes para se sobreporem ao movimento do grande capital no Nordeste, onde auferia grandes ganhos de monopólio em aliança com os governos estaduais. O projeto de desenvolvimento resultaria no desmonte de grupos oligárquicos que foram revitalizados pelos governos militares e que se reproduzem tal como a cana-de-açúcar. Implacável, a história dava o troco aos que ousavam romper com a moira. A volta de Furtado ao Nordeste tinha muito de trágico, como a volta de Katzanzakis a Creta. $\mathrm{O}$ imobilismo surge de uma profunda força telúrica que aparece no laconismo dos personagens de Euclides e fez com que Furtado considerasse a restauração do convento de São Francisco em João Pessoa como uma de suas maiores obras.

Diferente de muito que se tem dito a opção pelo questionamento teórico está registrada desde começos da década de 1950 pelos artigos no El Trimestre Económico, que ainda seriam em resposta à visão sutilmente colonial de ingleses e americanos $^{13}$. Não é uma opção circunstancial. Responde a uma necessidade de convalidação da teoria frente a revelação dos pontos de vista historicamente definidos das sociedades que herdaram uma posição periférica dos processos da colonização. A visão de teoria que se forma nas sociedades periféricas ao movimento geral do sistema não significa uma ruptura com as tradições da teoria senão uma leitura independente daquela que se desenvolveu na esfera da influência intelectual da nova ortodoxia que constitui uma renovação do marginalismo (Shackle, 1991).

\section{A FORMAÇÃO ECONÔMICA DO BRASIL}

Com a Formação Econômica o trabalho de Celso Furtado se desprende do marco geral do trabalho da CEPAL e se abre ao movimento mais amplo e profundo de construção histórica da América Latina. Também renova no uso de uma abordagem histórica afeita aos movimentos seculares. Caberá encontrar antecedentes nos trabalhos de Henri Pirenne, que projetaram nova luz sobre a continuidade essencial entre a Idade Média e o aparecimento da modernização, cuja obra era conhecida no círculo da CEPAL. É um desafio que toma as formas de recuperação da pluralidade do continente em sua formação secular e considera a variedade de movimentos e tendências que se introduzem ao longo da modernização e da industrialização. A escrita da história da América Latina mudou radicalmente com a incorporação de contribuições sobre a história pré-ibérica e com a abertura a outras fontes além das velhas metrópoles. O foco de Furtado é a colônia, cujo processo econômico tratou em seus dois eixos de relações internacionais e de relações internas, com sua territorialidade. Hoje se vê com mais clareza como esse processo colonial teve diferentes

\footnotetext{
13 "La formación de capital y el desarrollo económico", El Trimestre Económico, janeiro-março, 1953 e "Ensayo de interpretación histórico-analítica del desarrollo económico", abril-junho, 1956c.
} 
desdobramentos no tempo e efeitos colaterais, assumindo outras feições na construção e na atualização do bloco de poder dominante nas regiões do país.

A gênese desse livro é fundamental. Ele é um descolamento dessa busca teórica e surge no final de uma viagem pelo pensamento mundial e uma escolha do Brasil. O objeto-sujeito, o Brasil formado durante a colônia e firmemente assentado em experiências penosas apareceria com o estudo de "Análise e projeções do desenvolvimento econômico do Brasil" (1958), que o pôs diante da realidade brasileira. O sujeito é o Brasil em formação! Na abordagem de Celso Furtado a economia é o aspecto através do qual se dá o acesso à totalidade nacional. A categoria totalidade histórica é essencial. Pertence a uma metacrítica do conhecimento histórico. A percepção de totalidade sistêmica de Furtado tem a marca do estruturalismo francês, cujos pontos mais altos em economia foram André Marchal e François Perroux, com cujas obras era familiar. O essencial é a tradição que cobriu desde Descartes até Sartre e a estruturalistas como Goldmann e Sebag. Significa no essencial trabalhar sobre a visão de conjunto e, como diz Sartre o equilíbrio dinâmico está em relações causais que sustentam a mudança.

Mas é o peso das alternativas de política, que aparecem mais como oportunidades para ações decisivas, que descolam na passagem das especulações conceituais com a dura realidade da política econômica, em que é preciso aproveitar margens de decisão e confrontar racionalidade e irracionalidade. Somente na visão retrospectiva da Obra Autobiográfica Furtado recupera esta outra situação de um Brasil confrontado pela modernização (Furtado, 1997, vol.1, pp. 267-269). O diálogo com Roberto Campos é revelador das armadilhas ideológicas da época. Como se concilia a iniciativa de Campos em criar o BNDE e sua rejeição ao nacionalismo? Logicamente, repúdio à versão simples de nacionalismo usado como meio de proteger ganhos internos de monopólio. Furtado transmite certa perplexidade entre a opção - nele inevitável - pela internacionalidade e a escolha de uma estratégia de adesão ilustrada ao poderio norte-americano. Como deixou claro, o Brasil teria que navegar bordejando para evitar o confronto com o Adamastor do norte.

Nessa perspectiva, Furtado enfrentava um problema que tinha sido esquivado até então, qual seja o de questionar a identidade histórica do Nordeste e não só em seus aspectos geográficos ou culturais. Os que se colocaram essa questão, como Manoel Bonfim e Gilberto Freyre, não dispunham do instrumental econômico, ou como Rômulo Almeida que não se colocavam a questão da totalidade. Tal indefinição daria lugar a que alguns peritos, como diria Giddens, negassem a existência do Nordeste a partir de critérios ditos práticos. Certamente, havia um problema de como se apropriar dessa história, tradicionalmente fragmentada e dividida em torno de questões políticas de poder. Seria em torno de uma modernização conservadora ou de uma transformação social modernizadora? A grande originalidade de Furtado foi atingir o centro dessa questão e enfrentar as diversas coortes de interesses quase tribais de um bloco de poder acostumado a usar os partidos políticos como cascas que revestem poderes personalizados. Por isso, a primeira e grande reação contra o projeto de transformação sócia de Furtado veio de dentro da região, através de mobilizações de governadores que representavam interesses consorciados de grande propriedade com indústrias arcaicas subsidiadas.

A mola central da análise estrutural de Furtado, a aludida valorização do 
trabalho simples, seria um processo interno, que deveria ser alcançado de modo combinado com a incorporação de segmentos que não só alterassem as condições de produtividade como as de distribuição da renda. Observe-se que Furtado ainda falava em escassez de poupança em seus textos da década de 1950, mas passava a falar em evasão da formação de capital desde o ensaio "Uma política de desenvolvimento econômico e social para o Nordeste" (1959b). Nesse aspecto coincidia com Rômulo Almeida que falava de perdas em relações inter-regionais, mas que ainda não culpava os capitais regionais por transferirem seus ganhos para o Sudeste e para o exterior. Trata-se de identificar a responsabilidade histórica das elites nordestinas, que certamente não é pouca.

O cerne da questão não é produtividade senão o controle da formação de capital como Furtado reconheceria em seus textos posteriores à SUDENE e como Prebisch adiante, ao fazer as pazes com Marx em seu último artigo. Finalmente, o aumento de produtividade surge do modo como o capital usa o trabalho e não como uma iniciativa dos trabalhadores. Quando se coloca o tema da produtividade na perspectiva do trabalhador, na mecânica do processo trata-se de verificar como acontece o movimento que desloca as condições de distribuição da renda. Veremos que esses tropeços não desanimaram Furtado de identificar seu objeto-sujeito. Com a Formação Econômica do Brasil lançou um desafio ao pensar Brasil que não foi respondido, em primeiro lugar porque seus interlocutores não tinham a mesma vocação pela totalidade nem a mesma paixão pelo Brasil e em segundo lugar porque seria preciso contar com uma leitura crítica dos processos de poder que exigiriam outro esforço equivalente. A falta de uma análise da estruturação de classes da sociedade nordestina comprova uma modalidade regional de alienação que corresponde ao sucesso do bloco histórico de poder em se atualizar. Exemplos representativos desse fenômeno são o viés conservador que grassa nos cursos de economia da região junto com a falta de debates sobre a região e o país.

A busca de Furtado não parou nessa primeira barreira da produtividade, senão foi à contradição entre a formação de capital atual realizada por estas estruturas de empresas e o problema de política econômica. Já em 1972 (Furtado, 1968a, p. 55) faz uma opção clara a favor da teoria de Wicksell sobre a demanda de capital das empresas ante a teoria de empresário inovador de Schumpeter. Trata-se de um movimento orgânico do sistema em que as empresas avançam sobre o impulso inercial de formação de capital, onde tendem a repetir suas pautas de investimento. Dada a reconhecida tendência conservadora dos capitalistas fica como principal alternativa sua afeição por contratos públicos, não é difícil perceber que o verdadeiro agente de renovação é o Estado. Em seu livro conceitualmente mais profundo, Prefácio a uma Nova Economia Política (1976), Furtado dá continuidade a essa escolha teórica, ligando a demanda orgânica de capital das empresas a sua capacidade de acompanharem as transformações do mercado.

\section{ATUALIDADE E PERSPECTIVA HISTÓRICA}

A relação da CEPAL com a história foi frustrante. Desde a primeira formulação da teoria da relação centro-periferia pôs-se em pauta um eixo entre tecnologia 
e ideologia, em que o conhecimento de novas técnicas de planejamento se enfrentava com o poder soteriológico das utopias "realistas" a la Mannheim ou a la Francisco de Miranda, com passagem pela vocação à penitência do velho cristianismo ibérico. A CEPAL de Prebisch não conseguiu se situar no contexto histórico latino-americano, deixando-se prender ao médio prazo linear e anônimo do planejamento, apesar de que seus trabalhos principais surgiram quando o estudo da história de fortalecia no continente ${ }^{14}$. Uma possível explicação é o viés de dominação incorporado na modernização tecnológica, que foi denunciado por Myrdal (1968), mas que não foi percebido como mecanismo de poder pelos teóricos do desenvolvimento. A identificação de desenvolvimento com modernização, e desta com racionalidade instrumental, obstruiu a percepção da originalidade dos processos que produziram a unidade das nações. Uma crítica histórica da teoria do desenvolvimento seria um desdobramento inevitável, que revelaria contradições - e não só rupturas - entre as ações desenvolvidas em curto, médio e longo prazo, onde se defrontam diferentes condições de racionalidade. Houve uma grande dificuldade em conciliar a opção pela modernização com uma compreensão adequada do mundo pré-hispânico, porque ele representa traços civilizacionais que não são redutíveis à modernização tecnológica. Furtado utiliza exemplos europeus apesar de seu inegável conhecimento da América Latina e de sua conturbada experiência no México ${ }^{15}$. Surpreendeu, portanto, com sua história da economia latino-americana, em que se arriscou em voo solo em terrenos que Prebisch evitava por considerar impraticáveis. A construção histórica da América Latina revelou-se um problema muito maior que se vislumbrava no início da CEPAL, porque não podia prosseguir sem tomar em conta as dimensões não europeias do problema. A incorporação desses elementos históricos de referência explicitou as grandes diferenças de percepções nacionais que acabam sendo culturais e de classe. Mas há uma polêmica entre o que se pode definir como visões argentina e chilena da América Latina. O México tem uma visão sobre México e arredores, enquanto o Brasil continua com uma visão parcial e pouco informada do continente. Furtado tentou reproduzir seu estilo de abordagem, mas acabou caindo em uma simplificação historicamente útil, mas que apareceu no início do terremoto político iniciado em 1964 e que concluiu em 1984 com principais fossos em 1973 e 1976. Não escaparia dessa datação implacável, mas passaria a integrar um pequeno clube de historiadores econômicos dispostos a se arriscarem com hipóteses e interpretações. Nesse quadro de uma contemporaneidade turbulenta, a Formação Econômica paira como um belo momento de síntese cujas dificuldades estão delicadamente dissimu-

\footnotetext{
${ }^{14}$ Não há justificativa para que se tenha ignorado a obra de historiadores que teriam contribuído para uma visão mais adequada da formação do continente, como José Luis Romero, Eric Williams, Mariano Picón Salas, Caio Prado Jr., Sergio Buarque de Holanda. Nesse sentido, é preciso considerar que a CEPAL representou um encurtamento conceitual que a tornou mais vulnerável aos ataques de seus adversários neoclássicos e conservadores em geral.

${ }^{15}$ Alusão a sua recusa a modificar o Estudo Econômico do México quando confrontado com pressões do governo de então daquele país, que resultou em recusa da presidência a aceitar o trabalho.
} 
ladas. Hoje é como se tivesse sido fácil fazer aquele livro e não fosse ele a primeira e única resposta que se articulou até hoje aos Sertões.

\section{REFERÊNCIAS BIBLIOGRÁFICAS}

ALENCASTRO, Luiz Felipe (2000), O Trato dos Viventes, São Paulo: Companhia das Letras. BARRE, Raymond (1957) Économie Politique, 2 vols., Paris: Presses Universitaires de France. FURTADO, Celso (1953) “La formación de capital y el desarrollo económico”, El Trimestre Económico, México, enero-marzo.

FURTADO, Celso (1954a) "La teoria del desarrollo en la evolución de la teoria económica", El Trimeste Económico, México, julio-septiembre, pp. 241-264.

FURTADO, Celso (1954b) A Economia Brasileira, Rio de Janeiro: Editora A Noite.

FURTADO, Celso (1956a) “Análise e projeções da economia mexicana”, Relatório da CEPAL.

FURTADO, Celso (1956b) "El análisis marginal y la teoria del desarrollo", El Trimestre Económico, México, octubre-diciembre.

FURTADO, Celso (1956c) "Ensayo de interpretación histórico-analítica del desarrollo económico”, El Trimestre Económico, México, abril-junio.

FURTADO, Celso (1958) “Análise e projeções da economia brasileira”, Relatório da CEPAL.

FURTADO, Celso (1959a) “A operação Nordeste”, Rio de Janeiro: ISEB.

FURTADO, Celso (1959b) "Uma política de desenvolvimento econômico e social para o Nordeste", Ministério do Interior.

FURTADO, Celso (1959c) Formação Econômica do Brasil, Rio de Janeiro: Cultura.

FURTADO, Celso (1961) Desenvolvimento e Subdesenvolvimento, Rio de Janeiro: Cultura.

FURTADO, Celso (1967) La Economia Latinoamericana desde la Conquista hasta la Revolución Cubana, Santiago: Universitaria.

FURTADO, Celso (1968a) Teoria y Política del Desarrollo Económico, México: Siglo XXI.

FURTADO, Celso (1968b) Um Projeto para o Brasil, Rio de Janeiro: Saga.

FURTADO, Celso (1973) Racionalidade e Dependência, São Paulo: Paz e Terra.

FURTADO, Celso (1976) Prefácio a uma Nova Economia Política, Rio de Janeiro: Paz e Terra.

FURTADO, Celso (1987) Transformação e Crise na Economia Mundial, São Paulo: Paz e Terra.

FURTADO, Celso (1997) Obra Autobiográfica, 3 vols. São Paulo: Paz e Terra.

FURTADO, Celso (1999) O Longo Amanhecer, São Paulo: Paz e Terra.

FURTADO, Celso (2002) Raízes do Subdesenvolvimento, Rio de Janeiro: Civilização Brasileira.

GIANOTTI, José Arthur (2009) Marx além do Marxismo, Porto Alegre: LP\&M.

GIDDENS, Anthony (2002) Modernidade e Identidade, Rio de Janeiro: Jorge Zahar

HICKS, John (1965) Capital and Growth, Oxford: Oxford Press.

HOLANDA, Sergio Buarque de, org. (1993) História Geral da Civilização Brasileira, II. O Brasil Monárquico, 1. O processo de emancipação, Rio de Janeiro, Bertrand Brasil, 1993.

JAGER, Werner, (1984) Aristóteles, (1023) México:Fondo de Cultura Económica.

KAZANTZAKIS, Nikos (1965) Report do Greco, Nova York: Simon and Schuster.

MYRDAL, Gunnar (1968) Asian Dramma, An Inquiry into the Poverty of Nations, 3 vols., Nova York: Random House.

NURKSE, Ragnar (1964) Equilibrio y Crecimiento em la Economia Mundial, (1961) Madrid: Rialp.

PEDRÃO, F., MARINHO, L.C., RODRIGUEZ, O., BALTAR, A., (1988a) O Pensamento da CEPAL, Salvador: OEA/IANAMÁ.

PEDRÃO, Fernando (1988b) O pensamento da CEPAL, Salvador: UFBa/Ianamä.

SHACKLE, G.L.S. (1991) Origens da Economia Contemporânea. São Paulo: Hucitec. 